NBER WORKING PAPER SERIES

\title{
MEASURING UNEMPLOYMENT IN CRISIS: EFFECTS OF COVID-19 ON POTENTIAL BIASES IN THE CPS
}

\author{
Ori Heffetz \\ Daniel Reeves \\ Working Paper 28310 \\ http://www.nber.org/papers/w28310 \\ NATIONAL BUREAU OF ECONOMIC RESEARCH \\ 1050 Massachusetts Avenue \\ Cambridge, MA 02138 \\ December 2020
}

We thank participants in the Cornell Behavioral Economics Reading Group (BERG), Jerusalem Economics, Society, and Culture (JESC) lab, Authors Conference of the JOLE volume in honor of Alan Krueger, and especially our discussant, Judd Cramer, for comments that greatly improved the paper. We are grateful to Claire Gallagher for patiently responding to our questions regarding the CPS during COVID-19. Ophir Halperin and Doron Zamir provided research assistance. The authors have no financial or other material interests related to this research to disclose. The views expressed herein are those of the authors and do not necessarily reflect the views of the National Bureau of Economic Research.

NBER working papers are circulated for discussion and comment purposes. They have not been peer-reviewed or been subject to the review by the NBER Board of Directors that accompanies official NBER publications.

(C) 2020 by Ori Heffetz and Daniel Reeves. All rights reserved. Short sections of text, not to exceed two paragraphs, may be quoted without explicit permission provided that full credit, including $(\odot$ notice, is given to the source. 
Measuring Unemployment in Crisis: Effects of COVID-19 on Potential Biases in the CPS

Ori Heffetz and Daniel Reeves

NBER Working Paper No. 28310

December 2020

JEL No. C18,C83,I18,J60

\begin{abstract}
$\underline{\text { ABSTRACT }}$
From February to April 2020, as COVID-19 hit the U.S. economy, the official unemployment rate (UR) climbed from 3.5 percent - the lowest in more than 50 years-to 14.7 - the highest since current measurement began in January 1948. This unprecedented, speedy quadrupling of UR coincided with major disruptions in survey-data-collection procedures and a dramatic, differential drop in response rates. To what extent did measurement issues contribute to this quadrupling? We revisit two recently studied potential biases in the Current Population Survey: rotation group bias (Krueger, Mas and Niu, 2017) and difficulty-of-reaching bias (Heffetz and Reeves, 2019). We extend the original analyses to the years prior to the crisis and focus on the six months of peak UR, from April to September 2020. Our ballpark estimates suggest that the peak official UR figure could be biased by up to $\sim 1.5$ percentage points in either direction.
\end{abstract}

Ori Heffetz

S.C. Johnson Graduate School of Management

Cornell University

324 Sage Hall

Ithaca, NY 14853

and The Hebrew University of Jerusalem

and also NBER

oh33@cornell.edu

Daniel Reeves

Capital One

1600 Capital One Dr, 448F

McLean, VA 22102

dbr88@ cornell.edu 


\section{Introduction}

The COVID-19 pandemic that hit the U.S. in early 2020 led to an unprecedented spike in the official unemployment rate (UR). From 3.5 percent in February - the lowest since 1969 UR more than quadrupled to 14.7 percent in April - the highest since measurement began in 1948. It then declined by more than half over the next six months, to 6.9 percent by October.

In this paper, we ask: What effect, if any, did potential survey biases have on these figures? As Figure 1 shows, the spike in UR co-occurred with a similarly unprecedented, short-lived dip in response rates in the Current Population Survey (CPS) - on which the official UR is based. Trending down by around 1 percentage point a year in the previous decade to an average of 83 percent in the 12 months ending in February 2020, response rates dropped to 73 percent in March, continued dropping for three months to a low of 65 percent in June, and then quickly recovered (especially in September) to 80 percent by October. Behind this dramatic average dip, which coincided with major disruptions to survey-datacollection operations, were still more dramatic response-rate dips among certain respondent groups.

Figure 1: Unemployment Rate and Response Rates, Monthly

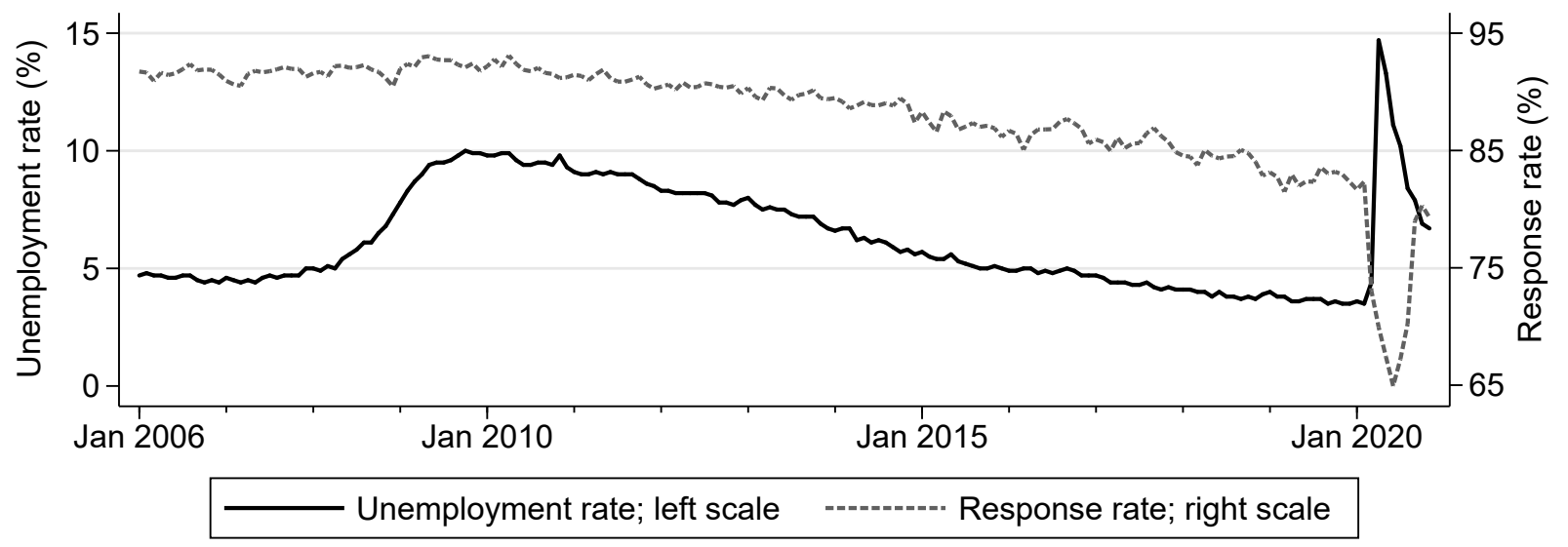

Notes: Monthly rates, January 2006-November 2020. Sources: Household response rate from Current Population Survey, January 2006-September 2020, and from BLS (2020a $)$ for October-November 2020. Unemployment rate (seasonally adjusted) from BLS (2020b).

Three coinciding elements of the 2020 spike could lead to increased biases in the official UR. First, for any existing multiplicative bias, whose magnitude grows proportionally with 
unemployment, a (true) spike in unemployment means a spike in the bias. Second, for any existing nonresponse bias, whose magnitude grows with nonresponse, a drop in response rates means an increase in the the bias. Third, any new, COVID-related changes - e.g., in survey procedures, respondent behavior, or sample composition-could themselves introduce new biases and affect the magnitude of existing ones.

In this paper, we focus on two potential biases in the official UR that received recent attention: rotation group bias (Krueger, Mas and Niu, 2017) and difficulty-of-reaching bias (Heffetz and Reeves, 2019). We explain them shortly. Past research suggests that the two (i) are multiplicative, hence their role is increased in times of peak unemployment; and (ii) may be related to nonresponse bias, whose role could double when the nonresponse rate doubles - as it did, from 17 percent pre-crisis to 35 percent in June 2020. We closely follow each of the above two papers' methodologies. We first extend their analysis, which ended in 2013-2014, to the pre-COVID years. Looking at 2006-2019, we find that these two potential multiplicative biases remained roughly unchanged by the eve of the COVID crisis. Based on this analysis, we ask a counterfactual: If these potential biases remained stable-i.e., extrapolating from 2006-2019 to 2020-how would they affect the official UR given the unemployment spike and response-rate drop?

We then turn to the six months of peak UR, from April to September. Analyzing these months both one by one and pooled together (as the half year consisting of the second and third quarters of 2020, or as two individual quarters), we look for a discontinuity in these potential biases relative to the pre-COVID years. Changes in the multiplicative factor, or slope, of rotation group bias would have to be dramatic to be detectable in a six-month sample; we do not identify such changes in our data. However, we do identify a dramatic change in the difficulty-of-reaching slope: it is almost twice as large in the April-September 2020 period as in 2006-2019. We discuss possible reasons. We then ask: Given our (noisy) slope estimate for the COVID period, what effect could this potential bias actually have on the official UR (given the unemployment spike and response-rate drop)?

In Section II we describe the CPS. It has two features that are central to our analysis. First, each household is interviewed eight times (in eight different months). Rotation group bias (Bailar, 1975, Krueger, Mas and Niu, 2017) is the tendency-quantified with an esti- 
mated slope - for the UR in a given month to be higher among households who are in their earlier rotation groups (i.e., their earlier interview months); all groups should be nationally representative samples. Second, the first of the eight interviews begins with an in-person visit, and the interviewer records the number of visit attempts required to complete the survey. Potential difficulty-of-reaching bias (Potthoff, Manton and Woodbury, 1993, Heffetz and Reeves, 2019) is the tendency of an outcome of interest to relate systematically, after controlling for other observables, to the difficulty of reaching a respondent (e.g., as measured by the number of contact attempts). In the UR case, the easier to reach tend to be more unemployed. This tendency, which we also quantify with a slope, may question the routinely made assumption that nonrespondents - effectively, the hardest to reach - are similar to the average respondent, i.e., the assumption of (conditional) random selection into the sample.

Still in Section II, we turn to discuss how COVID affected the CPS. Early-interview households were most impacted. First, the drop in response rates was most pronounced among households in early rotation groups, and especially among those in their first interview. Second, as in-person visits were partially or entirely suspended and replaced by phone interviews, the number of first-interview households for whom a difficulty-of-reaching measure is available dropped dramatically. Third, relatedly, we show that among households of known difficulty, the easiest to reach, who complete an interview after a single contact attempt, constitute a larger share than in the pre-COVID months. Finally, respondents' sociodemographic composition changed, especially among first-interview households. This compositional change has been recently studied by Ward and Edwards (2020), and we do not focus on it in this paper. Our analysis takes it into account: we use CPS survey weights to analyze rotation group bias, and we use adjusted means to analyze difficulty of reaching. We discuss other measures that we take, as well as remaining threats to our empirics resulting from these changes.

In Section III, we turn to rotation group bias. Closely following the analysis in Krueger, Mas and Niu (2017), the average slope we estimate for 2015-March 2020 is almost identical to the slope they estimate for 1994-2014. With only five years in our data relative to twenty years in theirs, our standard errors roughly double, but we estimate an almost identical slope also for a longer period, 2006-March 2020, with standard errors similar to theirs. We 
estimate a somewhat lower average slope based on the single half-year of peak UR, AprilSeptember 2020, but standard errors are large, and we cannot reject the null of no change during COVID. We can reject that the slope disappeared, reversed sign or, alternatively, dramatically increased.

In Section IV] we turn to potential difficulty-of-reaching bias. Closely following Heffetz and Reeves (2019), we estimate this bias from 2006 to 2019. Borrowing from Krueger, Mas and Niu (2017), we then use a regression framework to estimate a pre-COVID multiplicative slope: UR among the hardest to reach, once adjusting for demographics, is on average 0.79 $(\mathrm{S} . \mathrm{E} .=0.01)$ the rate among the easiest to reach. Turning to the COVID period, we then show that the slope almost doubled.

We discuss potential causes and implications of our findings in Section $\mathrm{V}$, where we also explain how our work relates to other recent work on CPS biases in the wake of COVID, and propose future directions. We open that concluding discussion by using our preferred estimates, as imprecise as they are, and combining them with several arguably reasonable assumptions, to return to our opening question: To what extent did measurement issues contribute to the dramatic, 11.2 percentage-point increase in the official UR from 3.5 percent in February to 14.7 in April 2020? Our ballpark estimates of rotation group bias suggest a possibly larger "real" UR increase, of 12.4 points; while those for difficulty of reaching suggest a possibly smaller "real" increase, which would have been 10.4 points had our preCOVID difficulty slope estimates remained stable but is estimated at 9.6 given the actual increased slope in the time of COVID.

\section{Current Population Survey (CPS)}

\section{II.1 Structure and Data}

The CPS is a monthly survey sponsored by the Bureau of Labor Statistics (BLS) and the U.S. Census Bureau. It provides several critical pulse checks of the health of the U.S. economy. Arguably the most closely watched among them is the official UR. Two important survey-design features of the CPS are central to our analysis. First, the survey is a rotating 
panel-each household is surveyed for four months, given an eight-month break, and then surveyed for four more months. Each of these eight interviews is referred to as a month-insample (MIS), from 1 to 8. During normal (pre-COVID) operations, each calendar month's sample consists of approximately equal shares from each MIS.11 Following Krueger, Mas and Niu (2017), we examine the systematic differences in the unemployment rates calculated using the different MIS samples for a given time period.

Second, the CPS samples addresses. An address's first interview (MIS 1) begins with an in-person visit, confirming the address's eligibility (e.g., ensuring that it belongs to a household rather than a business) and helping establish an interviewing relationship with the household. Subsequent interviews are typically conducted by phone, except for the interview after the eight-month break (MIS 5), which is usually completed in person. For in-person interviews, the surveyor manually records the number of visit attempts required to complete the survey. Following Heffetz and Reeves (2019), we use this number for MIS 1 as our measure of a household's difficulty of reaching.$^{2}$

For each household's interview, the interviewer asks the "most knowledgeable" member of the household to create a roster of household members and answer questions to determine the labor force status of each (CPS, 2015). In particular, the questions determine whether or not a household member was employed in the interview month's reference week (typically the week containing the 12 th of the month). If she was, she is coded as employed. if not, then further questions determine whether she was both actively looking for work in the past four weeks and available for work during the reference week. If she was, she is coded as unemployed. Otherwise, if she neither worked nor was actively looking for and available to work, she is coded as out of the labor force. Our primary outcome of interest-the unemployment rate- is defined as the share of unemployed in the labor force (employed plus

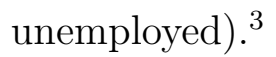

\footnotetext{
${ }^{1}$ As Table 1 below will show, response rates for households that entered MIS 1 during the early months of the pandemic were much lower than those already in a later MIS when the pandemic started, causing an unequal distribution of MIS shares within each month during the pandemic.

${ }^{2}$ Following Heffetz and Reeves (2019), our difficulty-of-reaching analysis includes only MIS 1 households, both because we have the difficulty measure only for in-person attempts and to avoid potentially confounding issues of rotation group bias in the difficulty-of-reaching analysis.

${ }^{3}$ Throughout the paper, we use BLS's unemployment rate (U-3). However, as we mention below, for some of our analysis we also looked at broader measures of labor underutilization reported by the BLS (U-4, U-5,
} 
We analyze almost fifteen years of CPS data, from April 2006 to September 2020. Following Krueger, Mas and Niu (2017), for our rotation group bias analysis we use all observations that the BLS includes when calculating the labor force participation and unemployment rates - non-institutionalized civilians, aged 16 and up - resulting in a sample of 17,806,200 observations, of whom 11,363,263 (63.8 percent) are in the labor force. Following Heffetz and Reeves (2019), for our difficulty-of-reaching analysis, we only keep from that sample the 2,162,152 MIS 1 observations, of whom 1,405,889 (65.0 percent) are in the labor force. We use the same difficulty measure as in Heffetz-Reeves: a variable recording the "number of actual and attempted personal contacts." 4 In our MIS 1 sample, it is missing for 9.9 percent of the observations; their difficulty is reported below as "None Reported," or "NR." For the remainder of the observations it records 1-9 (top coded) contact attempts. We split them into three categories: 1 attempt (62.9 percent of our sample), 2 attempts (16.8 percent), and 3 or more attempts (10.4 percent).

\section{II.2 COVID's Effect on Data Collection and Sample}

The initial effects of COVID on CPS data-collection operations were felt during March 2020. Interviews began on March 15 and in-person interviews were officially suspended on March 20. "Additionally, the two Census Bureau call centers that assist with telephone interviewing were closed. The Census Bureau continued to conduct the household survey by telephone and made efforts to collect telephone interviews for households that would normally have been interviewed in person" (CPS, 2020a). The response rate steeply declined, from 83 percent in the preceding twelve months to 73 percent in March (see Table 1), as did the share of in-person interviews, from 75 percent in the preceding two months to 44 percent (Table 2). The response rate continued declining and reached an all-time low of 65 percent in June. Beginning in July, in-person interviews were restarted in some locations, and the response rate began to recover; by September, 54 percent of MIS 1 interviews were conducted in person, and the overall response rate was not too far below its pre-COVID level, at 79

and U-6), and found our results to be qualitatively similar. See CPS $(2020 b)$ for definitions.

${ }^{4}$ As discussed in Heffetz and Reeves (2019) this variable, which is manually recorded by interviewers, is a noisy measure of difficulty; in principle, it does not include telephone contact attempts, and it is more generally subject to errors, both intentional and unintentional. 
percent. 5

Table 1: CPS Response Rates by MIS

\begin{tabular}{lccccccccc}
\hline \hline & Overall & MIS 1 & MIS 2 & MIS 3 & MIS 4 & MIS 5 & MIS 6 & MIS 7 & MIS 8 \\
\hline A. Response rates & & & & & & & & & \\
Mar 2019-Feb 2020 avg & 82.5 & 80.1 & 83.1 & 83.7 & 83.8 & 80.7 & 82.4 & 82.7 & 83.6 \\
March 2020 & 73.0 & 56.8 & 74.2 & 77.3 & 77.5 & 68.6 & 75.2 & 76.0 & 78.6 \\
April 2020 & 69.9 & 46.7 & 63.5 & 75.7 & 78.2 & 68.6 & 72.7 & 76.2 & 78.1 \\
May 2020 & 67.4 & 47.8 & 56.4 & 67.7 & 76.5 & 68.3 & 71.4 & 73.7 & 77.7 \\
June 2020 & 64.9 & 48.4 & 55.8 & 60.7 & 68.9 & 68.4 & 70.9 & 72.0 & 74.3 \\
July 2020 & 67.2 & 54.2 & 61.0 & 64.3 & 66.6 & 70.4 & 72.4 & 73.7 & 75.1 \\
August 2020 & 70.2 & 60.0 & 65.0 & 67.5 & 69.1 & 72.9 & 74.8 & 75.7 & 76.9 \\
September 2020 & 79.0 & 73.4 & 77.3 & 77.8 & 79.2 & 78.8 & 81.5 & 81.4 & 82.6 \\
Oct 2020-Nov 2020 avg & 79.8 & 74.5 & 77.8 & 79.4 & 80.1 & 79.0 & 81.1 & 82.5 & 83.9 \\
B. Percentage point difference from & Mar 2019-Feb 2020 average & & & & \\
March 2020 & -9.5 & -23.3 & -8.9 & -6.4 & -6.3 & -12.1 & -7.3 & -6.6 & -5.0 \\
April 2020 & -12.6 & -33.4 & -19.6 & -8.0 & -5.6 & -12.1 & -9.7 & -6.5 & -5.5 \\
May 2020 & -15.1 & -32.4 & -26.7 & -16.0 & -7.3 & -12.4 & -11.1 & -9.0 & -5.9 \\
June 2020 & -17.6 & -31.7 & -27.3 & -23.0 & -14.9 & -12.3 & -11.5 & -10.6 & -9.3 \\
July 2020 & -15.3 & -25.9 & -22.1 & -19.4 & -17.3 & -10.3 & -10.0 & -8.9 & -8.5 \\
August 2020 & -12.3 & -20.1 & -18.0 & -16.2 & -14.7 & -7.8 & -7.7 & -7.0 & -6.7 \\
September 2020 & -3.5 & -6.7 & -5.8 & -5.9 & -4.6 & -1.9 & -1.0 & -1.2 & -1.0 \\
Oct 2020-Nov 2020 avg & -2.7 & -5.7 & -5.3 & -4.3 & -3.8 & -1.7 & -1.3 & -0.2 & 0.3 \\
\hline
\end{tabular}

Notes: Source: "Impact of the coronavirus (COVID-19) pandemic on The Employment Situation for November 2020," www.bls.gov/covid19/employment-situation-covid19-faq-november-2020.htm.

The reduction in response rate was particularly acute for MIS 1, where rates went from around 80 percent prior to March to 47-48 percent in April through June. Historically, response rates for MIS 1 and 5, the months when the address is being contacted for either the first time or the first time after a long break, have been the lowest. Response rates then generally increase through the MIS 2-4 period and then again through the MIS 6-8 period as the interviewing relationship and contacts are better established. This qualitative pattern continued during the COVID period, but, notably, cohorts that had already been contacted prior to COVID (i.e., not in MIS 1 or 5) suffered much smaller declines in response rates than those that were beginning or restarting during COVID. While cohorts that began during COVID also had higher response rates the longer they were in the survey, their rates remained substantially below those that had their contact (re-)established prior to COVID.

\footnotetext{
${ }^{5} \mathrm{~A}$ limited number of interviews in April, May, and June are still coded as in-person (see Table 2); they are believed to be erroneously coded by the interviewer.
} 
Table 2: Difficulty of Reaching and Interview Mode by Month, MIS 1, 2020

\begin{tabular}{|c|c|c|c|c|c|c|c|c|c|}
\hline & Jan & $\mathrm{Feb}$ & Mar & Apr & May & Jun & Jul & Aug & Sep \\
\hline \multicolumn{10}{|c|}{ A. Difficulty of reaching } \\
\hline 1 attempt & $\begin{array}{c}7,175 \\
63.0 \%\end{array}$ & $\begin{array}{c}7,201 \\
62.5 \%\end{array}$ & $\begin{array}{c}4,805 \\
58.5 \%\end{array}$ & $\begin{array}{c}376 \\
5.4 \%\end{array}$ & $\begin{array}{c}310 \\
4.4 \%\end{array}$ & $\begin{array}{c}297 \\
4.1 \%\end{array}$ & $\begin{array}{c}1,338 \\
16.7 \%\end{array}$ & $\begin{array}{c}2,178 \\
25.0 \%\end{array}$ & $\begin{array}{c}5,346 \\
51.0 \%\end{array}$ \\
\hline 2 & $\begin{array}{c}1,773 \\
15.6 \%\end{array}$ & $\begin{array}{c}1,814 \\
15.8 \%\end{array}$ & $\begin{array}{c}684 \\
8.3 \%\end{array}$ & $\begin{array}{c}34 \\
0.5 \%\end{array}$ & $\begin{array}{c}28 \\
0.4 \%\end{array}$ & $\begin{array}{c}46 \\
0.6 \%\end{array}$ & $\begin{array}{c}273 \\
3.4 \%\end{array}$ & $\begin{array}{c}445 \\
5.1 \%\end{array}$ & $\begin{array}{c}1,174 \\
11.2 \%\end{array}$ \\
\hline $3+$ & $\begin{array}{l}1,097 \\
9.6 \%\end{array}$ & $\begin{array}{c}1,158 \\
10.1 \%\end{array}$ & $\begin{array}{c}155 \\
1.9 \%\end{array}$ & $\begin{array}{c}48 \\
0.7 \%\end{array}$ & $\begin{array}{c}28 \\
0.4 \%\end{array}$ & $\begin{array}{c}17 \\
0.2 \%\end{array}$ & $\begin{array}{c}156 \\
1.9 \%\end{array}$ & $\begin{array}{c}207 \\
2.4 \%\end{array}$ & $\begin{array}{c}552 \\
5.3 \%\end{array}$ \\
\hline Unknown & $\begin{array}{c}1,341 \\
11.8 \%\end{array}$ & $\begin{array}{c}1,344 \\
11.7 \%\end{array}$ & $\begin{array}{c}2,569 \\
31.3 \%\end{array}$ & $\begin{array}{c}6,522 \\
93.4 \%\end{array}$ & $\begin{array}{c}6,747 \\
94.9 \%\end{array}$ & $\begin{array}{c}6,883 \\
95.0 \%\end{array}$ & $\begin{array}{c}6,246 \\
77.9 \%\end{array}$ & $\begin{array}{c}5,874 \\
67.5 \%\end{array}$ & $\begin{array}{c}3,419 \\
32.6 \%\end{array}$ \\
\hline \multicolumn{10}{|c|}{ B. Interview mode } \\
\hline In-person & $\begin{array}{c}8,536 \\
75.0 \%\end{array}$ & $\begin{array}{l}8,590 \\
74.6 \%\end{array}$ & $\begin{array}{c}3,584 \\
43.6 \%\end{array}$ & $\begin{array}{c}259 \\
3.7 \%\end{array}$ & $\begin{array}{c}217 \\
3.1 \%\end{array}$ & $\begin{array}{c}226 \\
3.1 \%\end{array}$ & $\begin{array}{c}1,318 \\
16.4 \%\end{array}$ & $\begin{array}{c}2,169 \\
24.9 \%\end{array}$ & $\begin{array}{c}5,653 \\
53.9 \%\end{array}$ \\
\hline Telephone & $\begin{array}{c}2,794 \\
24.5 \%\end{array}$ & $\begin{array}{c}2,881 \\
25.0 \%\end{array}$ & $\begin{array}{c}3,538 \\
43.1 \%\end{array}$ & $\begin{array}{c}5,894 \\
84.4 \%\end{array}$ & $\begin{array}{c}6,828 \\
96.0 \%\end{array}$ & $\begin{array}{c}6,980 \\
96.4 \%\end{array}$ & $\begin{array}{c}6,648 \\
83.0 \%\end{array}$ & $\begin{array}{c}6,404 \\
73.6 \%\end{array}$ & $\begin{array}{c}4,785 \\
45.6 \%\end{array}$ \\
\hline Unknown & $\begin{array}{c}56 \\
0.5 \%\end{array}$ & $\begin{array}{c}46 \\
0.4 \%\end{array}$ & $\begin{array}{c}1,091 \\
13.3 \%\end{array}$ & $\begin{array}{c}827 \\
11.8 \%\end{array}$ & $\begin{array}{c}68 \\
1.0 \%\end{array}$ & $\begin{array}{c}37 \\
0.5 \%\end{array}$ & $\begin{array}{c}47 \\
0.6 \%\end{array}$ & $\begin{array}{c}131 \\
1.5 \%\end{array}$ & $\begin{array}{c}53 \\
0.5 \%\end{array}$ \\
\hline Total & 11,386 & 11,517 & 8,213 & 6,980 & 7,113 & 7,243 & 8,013 & 8,704 & 10,491 \\
\hline
\end{tabular}

Notes: Source: Current Population Survey, January 2020-September 2020. Sample: MIS 1. Panel A: number of in-person contact attempts. Panel B: contact mode for household's last MIS 1 interview. Percentages are calculated within panel and month.

These changes in response behavior and interview mode have implications for both the study and impact of the two biases we examine. First, the (partial or full) suspension of in-person data collection limits the amount of available difficulty-of-reaching data during April to July — when the UR was at its highest - as our difficulty variable records in-person visit attempts. Second, this shrinkage of the sample of respondents with known difficulty is accompanied by a composition change: its share of easier-to-reach respondents increased. Figure 2 shows that in January-February, the 1-attempt share was roughly four times the 2-attempt share and six times $3+$ share; in July-September it was five times and ten times, respectively, the 2-attempt and 3+ shares. Third, the fact that earlier MIS - that typically have higher unemployment rates - make up a smaller share of the sample during the pandemic may change the impact of rotation group bias on the overall UR ${ }^{6}$

\footnotetext{
6 Ward and Edwards (2020) show that this is true even after the weighting done by CPS: examining weighted sample sizes for each MIS, they find that early cohorts have substantially smaller weighted samples than later cohorts.
} 
Finally, the onset of the pandemic marked a shift in the demographic composition of the CPS sample, particularly among MIS 1 respondents, who had the largest drop in response rate. Figure 2 shows that initially, the share of MIS 1 respondents that were Black fell by 3 percentage points (a decrease of 27 percent relative to pre-COVID levels). The share in the oldest age category, 65 or more, increased markedly (by about 6 percentage points) while the share of the 20-39 group had a corresponding fall (of 4 percentage points). Similarly, the share of those in the highest education group, bachelor's degree or more, initially increased while those with less than high school education decreased (both by around 3 percentage points). Appendix Table A.1 shows the somewhat more muted demographic effects in the entire sample for this period. See Ward and Edwards (2020) for further discussion of demographic changes in the CPS during COVID; and Berchick, Mykyta and Stern (2020) and Rothbaum and Bee (2020) for the closely related changes in the CPS Annual Social and Economic Supplement (CPS ASEC).

To the extent possible, our analysis below takes these effects of COVID into account. For example, we estimate bias slopes during COVID both at the monthly level and at the half-yearly level - trading sample frequency against size - and both with and without CPS weights. In addition, in our difficulty-of-reaching analysis, we use adjusted means to control, at least to some extent, for changes in sample composition. Our analysis should therefore be robust, in principle, to demographic shifts. However, we warn that changes in observable characteristics may hint of changes in the unobservable characteristics of those who did and did not respond to the survey during COVID - changes that, by their nature, cannot be handled by sampling frequency, weighting, or controlling for observables. At the same time, and for the same reason, these sample-composition and other changes may cast doubt on the default assumption of (conditional) random nonresponse - highlighting the importance of our investigation, in particular in the time of COVID, in spite of the data limitations. 
Figure 2: CPS Demographics, MIS 1
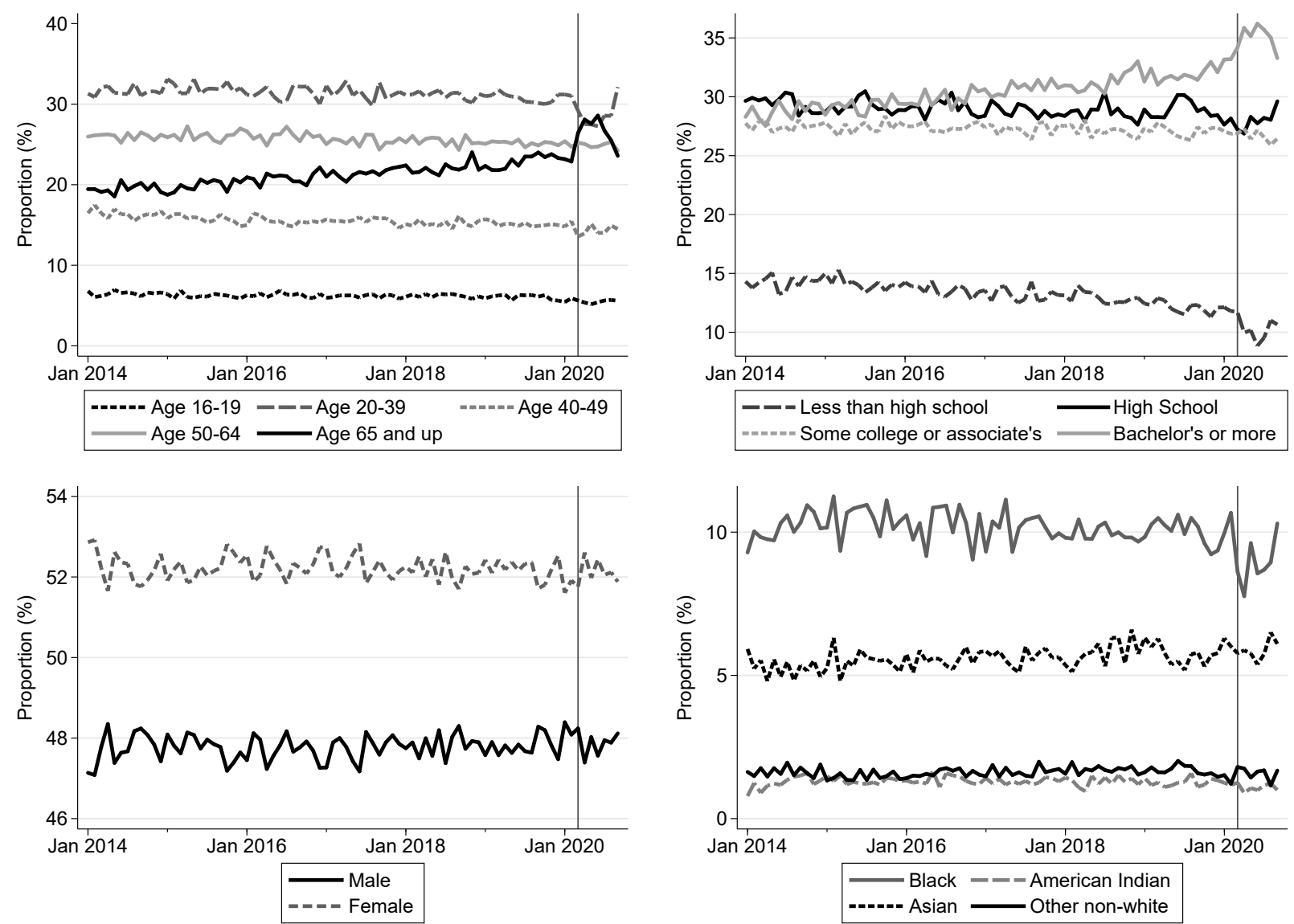

Notes: Source: Current Population Survey, January 2014-September 2020. Sample: MIS 1 participants. Share in each demographic group (share White not graphed). Vertical line at March 2020.

\section{Rotation Group Bias}

\section{III.1 Pre-COVID}

Krueger, Mas and Niu (2017) examine rotation group bias in the CPS for 1976-2014. They note that Bailar (1975) was among the first to document it. It is the empirical observation that within a given time period, the unemployment rate displays a decreasing pattern across MIS. Applying their analysis to half-year periods in our 2006-2020 sample, Figure 3 shows that MIS 1 unemployment rate (solid circle) is the highest in almost all half-year periods.7 For each period, the MIS 1-4 rates (darker, solid shapes in the graph) also tend to be above the MIS 5-8 rates (lighter, hollow shapes), with the main exception that at times MIS 4 flips

\footnotetext{
${ }^{7}$ In order to facilitate the analysis in the COVID period, the half-year periods are October to March, and April to September.
} 
positions with MIS 5 (the "restart" interview).

Figure 3: Unemployment Rate by MIS

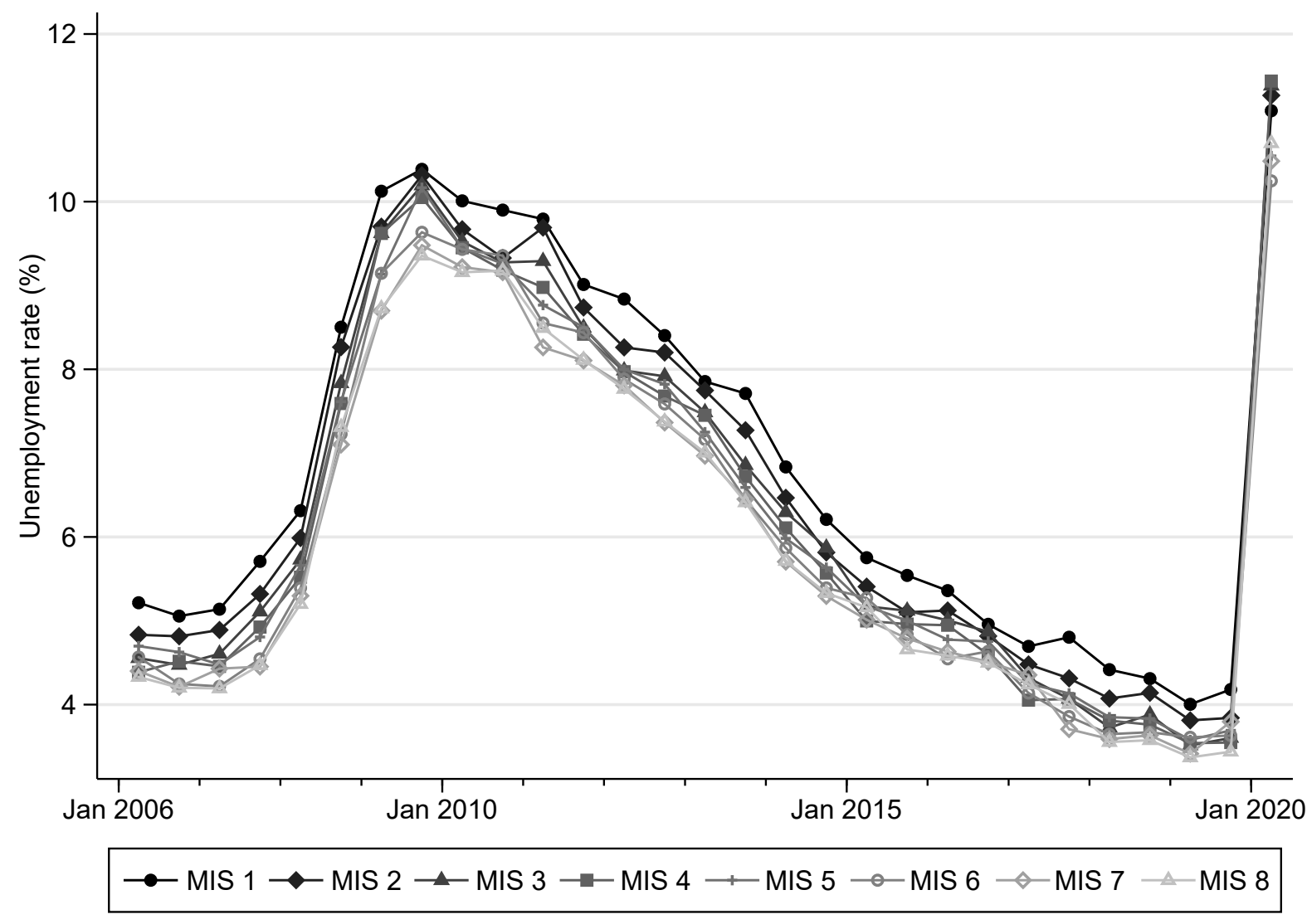

Notes: Source: Current Population Survey, April 2006-September 2020. Sample: All labor force participants. Unemployment rate calculated for each half-year by MIS. Half-year periods are April-September and October-March.

To quantify the bias, Krueger, Mas and Niu (2017) calculate a multiplicative index. It takes the average unemployment rate calculated for each MIS separately and divides it by the average of the eight MIS-specific average rates (and multiplies by 100). If the average unemployment rate in a given MIS were equal to the average across all eight, then the MIS would have an index of 100; higher and lower numbers, respectively, indicate a higher and lower average unemployment rate in that MIS relative to the average of all MIS. Krueger, Mas and Niu (2017) find an average downward slope of -1.85 (S.E. $=0.05)$ in the index from one MIS to the next in the 1994-2014 period; the MIS 1 index in that period is on average 109, while the MIS 8 index is 95 . Estimating a time trend, they find that the bias 
is slightly larger in later years.

We repeat their main analysis for three different periods. Table 3, whose structure replicates the relevant parts from their Table 2, reports our results. We start with two preCOVID periods: 2006-March 2020 (Panel A) and 2015-March 2020 (Panel B); this more recent "update period" does not overlap with the years studied in Krueger, Mas and Niu (2017). The two yield similar results that closely replicate the original results: for 2015March 2020, we find an almost strictly monotonic trend across MIS, with only a slight uptick in the indices between MIS 4 and 5; an estimated slope across MIS of -1.97 (S.E. $=0.12$ ); and an average index range from 111 in MIS 1 to 95 in MIS 8. We conclude that the rotation group bias documented in Krueger, Mas and Niu (2017) for 1994-2014 seems to extend to the eve of COVID.

Table 3: Multiplicative Indices for the Unemployment Rate by MIS

\begin{tabular}{|c|c|c|c|c|c|c|c|c|c|c|}
\hline MIS 1 & MIS 2 & MIS 3 & MIS 4 & MIS 5 & MIS 6 & MIS 7 & MIS 8 & Avg. & Slope & S.E. \\
\hline \multicolumn{11}{|c|}{ A. $2006-$ March 2020} \\
\hline 110.1 & 104.7 & 101.1 & 98.7 & 99.4 & 96.5 & 95.0 & 94.5 & 6.1 & -2.03 & 0.06 \\
\hline \multicolumn{11}{|c|}{ B. 2015-March 2020} \\
\hline 111.2 & 104.4 & 99.8 & 97.7 & 99.5 & 96.7 & 95.8 & 94.8 & 4.3 & -1.97 & 0.12 \\
\hline \multicolumn{11}{|c|}{ C. April-September 2020} \\
\hline 101.8 & 103.4 & 104.5 & 105.0 & 96.8 & 94.1 & 96.2 & 98.2 & 10.9 & -1.19 & 0.28 \\
\hline
\end{tabular}

Notes: Source: Current Population Survey, April 2006-September 2020. Sample: labor force participants. Half-yearly multiplicative indices for unemployment rate, calculated by dividing the rate in a given MIS by the simple average of the 8 MIS-specific rates. Slope measures the average change in the index from one MIS to the next. The slope's standard error is calculated using 100 bootstrap iterations.

\section{III.2 COVID Update}

Krueger, Mas and Niu (2017) find evidence that rotation group bias is correlated with nonresponse rate both across time (rotation group bias increases with with nonresponse rate) and cross-sectionally (the bias is larger for groups with higher nonresponse rates) 8 They also find a discontinuity in rotation group bias that occurred when the survey was

\footnotetext{
${ }^{8}$ Consistent with this correlation, Krueger, Mas and Niu (2017) find a reduction in rotation group bias among individuals who participate in all 8 MIS. We cannot replicate that analysis during COVID, as it requires 15 months after a MIS 1 cohort enters the sample for them to finish their MIS 8 interview.
} 
redesigned in 1994 and nonresponse rates suddenly increased from around 4 percent to around 6. Therefore, it was possible that the dramatic shifts in response rates caused by COVID might also be associated with a dramatic change in the bias. To examine this possibility, Panel C of Table 3 reports a third time period: the half-year from April to September 2020.

Panel $\mathrm{C}$ is based on very little data. The smallest unit of data aggregation in Krueger, Mas and Niu (2017) is a full year, and their original Table 2 analyzes two time periods: one 18 years long (1976-1993) and another 21 years long (1994-2014)—reflecting the difficulty to meaningfully estimate rotation group bias with shorter periods. In sharp contrast, our results in Panel $\mathrm{C}$ are based on a single half-year observation. Our results are therefore based on only 2-3 percent as many months of data as the original analysis - and at a period of particularly small monthly samples due to the dip in response rate. (Similarly, Panel C is based on less than 10 percent of the observations Panel B is based on.) The analysis in Panel $\mathrm{C}$ can therefore serve to identify only dramatic changes in rotation group bias during the COVID half-year - changes that a priori could not be ruled out, given all that occurred in the CPS and in the economy. However, Panel C shows no such dramatic changes. The estimated slope decreases to -1.19 (S.E. $=0.28)$, remaining negative; and the original almost-strictly monotonic decline of the average indexes from MIS 1 to MIS 8 is now a noisy decline.

To put this COVID half-year data point further in context, Figure 4 presents it as the rightmost among all half-year slope estimates in 2006-2020. This figure (inspired by Figure 2 in Krueger, Mas and Niu (2017)) makes it clear that the typical variation in rotation group bias from one half-year to the next in the pre-COVID period is similar to the change from the last pre-COVID half-year to the COVID half-year $9^{9}$ The figure also shows that half-year slopes smaller than -1.19 (in absolute value) are not unusual. ${ }^{10}$

Finally, as shown in Ward and Edwards (2020) and mentioned above, the construction of

\footnotetext{
${ }^{9}$ Regression analysis, modeled after Krueger, Mas and Niu (2017)'s Table 1 and presented in our Appendix Table A.1, uses quarterly data and shows no statistically significant difference in rotation group bias before vs. during COVID. (We use quarterly rather than half-yearly data so we can also assess a two-point "time trend" during COVID.) Using a linear-time-trend model, we test two specifications allowing for a level shift for the two COVID quarters, with and without a break in the time trend. Neither specification shows a statistically significant change.

${ }^{10}$ We additionally looked for any change during COVID in rotation group bias in the broader UR measures reported by the BLS: U-4, U-5, and U-6. While the slopes of rotation group bias, both before and during COVID, are slightly different for each measure, the results are all qualitatively similar and the change during COVID seems well within the typical period-to-period variation.
} 
Figure 4: Rotation Group Bias Over Time

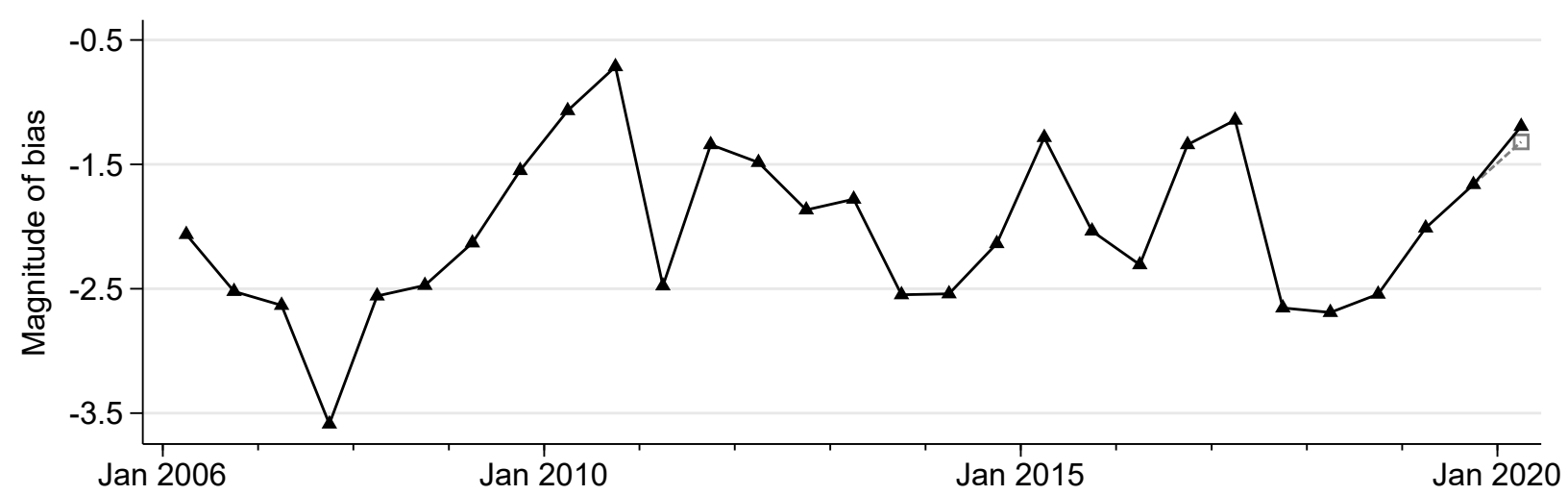

Notes: Source: Current Population Survey, April 2006-September 2020. Slope, or magnitude, of rotation group bias at the half-year level. Half-year periods are April-September and October-March. Rightmost data point: hollow square represents slope calculated at the monthly level and averaged for the COVID half-year of April-September 2020.

CPS sample weights leads to a relative underweighting of early-MIS observations during the COVID peak unemployment and a corresponding overweighting of later-MIS ones. In the construction of the index, all of a given MIS's observations are pooled to calculate that MIS's unemployment rate for the period. During COVID, this causes early MIS to have relatively fewer of their total observations during the months of highest unemployment, while later MIS have a relatively larger share of their total observations during highest unemployment - an effect that could mechanically lower the observed rotation group bias. Estimating the bias at the monthly level eliminates this concern. Figure 4 s rightmost data point, the COVID half-year, is also drawn as the average of six monthly-level estimates (hollow square). This half-year slope average, -1.32 , is slightly closer to the pre-COVID average.

In summary, we find no dramatic shift in rotation group bias during COVID, in spite of the differential spikes in nonresponse rates and other COVID-related changes. Much more data would be required to identify a moderate shift; however, the quick return of response rates (among other things) to pre-COVID levels seems to preclude the possibility of such additional data, at least at the time of writing. 


\section{Difficulty of Reaching}

\section{IV.1 Pre-COVID}

Heffetz and Reeves (2019) study three large-scale government surveys and document a systematic relationship between the difficulty of reaching respondents and outcomes of interest. In particular, they find an association between the number of visit attempts and the MIS 1 unemployment rate in the 1994-2013 CPS data: unemployment rates among the difficult to reach are consistently lower, once sociodemographic differences between the groups are accounted for. We begin our analysis by examining this association since 2014 . We do so by recreating the primary analysis from Heffetz and Reeves (2019), first for 2014-March 2020 as a single pre-COVID, "update" period, and then within each half-year period from 2006 to September 2020. The latter provides a higher-resolution analysis over a longer period, and adds the COVID half-year as its own period.

Within each analysis period, we run a regression where the dependent variable is the unemployment rate and the covariates are a long list of sociodemographic and other variables, fully interacted with the difficulty-of-reaching categories ${ }^{11}$ Each period's regression results are then used to calculate that period's adjusted mean for each difficulty group. A difficulty group's adjusted mean is the population's average unemployment rate that would be predicted by the model under the counterfactual assumption that the entire population had that group's difficulty. Intuitively, it is as if all observations have their difficulty variable counterfactually set to have a certain difficulty, but all their other sociodemographic and other variables are kept at their (true) values; each observation's predicted value of the dependent variable is then calculated, and all predicted values are averaged. This technique allows us to control for known demographic differences between those who are easy and those who are hard to reach. For instance, the easy to reach tend to be older and less well-educated than the hard to reach 12

Table 4, which replicates Table 3 in Heffetz and Reeves (2019), reports our estimates for

\footnotetext{
${ }^{11}$ The demographics interacted with difficulty categories are: age, children in household, female, education, race, household size, marital status, state, urban/rural, interview month, and interview year (for the pooled 2014-2020 regression).

${ }^{12}$ See Heffetz and Reeves (2019) for a more detailed discussion of the demographic differences in the CPS, as well as the adjusted-means approach.
} 
the 2014-March 2020 period. Panel A reports the estimated coefficients from the (single) regression described above. Column 1 reports the base effect of each demographic covariate, while columns 2-4 report the interaction between the demographic covariate and a given difficulty category (2 attempts, $3+$ attempts, and None Reported, respectively; 1 attempt is the omitted category). Panel B reports the adjusted means, calculated using the regression from Panel A.

Beginning with Panel B, it shows a trend in the adjusted mean of the UR across difficultyof-reaching groups. The UR is 1.4 percentage points higher among the easiest- vs. the hardest-to-reach, 5.4 vs. 4.0 percent; the middle difficulty group lies in between, closer to the easiest group, at 4.9 percent (all S.E.s $\approx 0.1$ percent or less). Panel A shows limited evidence, if any, that this UR-difficulty trend varies systematically across demographic groups: there are no monotonic trends with significance. These results are similar to those in Heffetz and Reeves (2019). For example, for 2012-2013, they find a similar, 1.5 percentage point UR difference between the easiest- (8.0 percent) and hardest-to-reach (6.5 percent), with the middle group in between and closer to the former $(7.5$ percent). The base coefficients are also similar: for example, teenagers are 6.5 percentage points $(\mathrm{S} . \mathrm{E} .=0.3)$ more likely to be unemployed than those 40-49 (the omitted age category) in our data, compared with 7.9 percentage points $($ S.E. $=0.7)$ in $2012-201313$

Figure 5(modeled after Figure 1 in Heffetz and Reeves (2019)) graphs the adjusted means for each half-year period from 2006 to September 2020. It shows that the difficulty gradient originally documented for 1994-2013 extends within virtually every half-year throughout the entire pre-COVID period (i.e., excluding the rightmost data point, discussed in the next subsection). The easiest-to-reach group has a markedly higher adjusted-mean UR than the hardest-to-reach group, with a difference that appears multiplicative, at roughly one-fifth of the UR of the easiest-to-reach. Again, the 2-attempt group generally lies between the 1-attempt and the 3-or-more-attempts group, closer to the former.

\footnotetext{
${ }^{13}$ While reported mainly for completeness, the adjusted mean of the NR category was in the original data, and remains in our data, indistinguishable from that of the hardest-to-reach category. (Recall, the NR, or None Reported category includes all respondents for whom difficulty information is not available.)
} 
Table 4: Unemployment Rate by Difficulty

\begin{tabular}{|c|c|c|c|c|}
\hline Attempts & 1 & 2 & $3+$ & NR \\
\hline \multicolumn{5}{|l|}{ A. Regression with interactions } \\
\hline & Base & \multicolumn{3}{|c|}{ Interactions } \\
\hline Age: $16-19$ & $\begin{array}{c}0.065 \\
(0.003)\end{array}$ & $\begin{array}{l}0.000 \\
(0.007)\end{array}$ & $\begin{array}{l}-0.008 \\
(0.008)\end{array}$ & $\begin{array}{l}-0.002 \\
(0.010)\end{array}$ \\
\hline $20-39$ & $\begin{array}{c}0.010 \\
(0.001)\end{array}$ & $\begin{array}{l}-0.002 \\
(0.002)\end{array}$ & $\begin{array}{c}0.000 \\
(0.002)\end{array}$ & $\begin{array}{l}-0.006 \\
(0.002)\end{array}$ \\
\hline $50-64$ & $\begin{array}{c}0.000 \\
(0.001)\end{array}$ & $\begin{array}{l}-0.003 \\
(0.002)\end{array}$ & $\begin{array}{l}-0.003 \\
(0.002)\end{array}$ & $\begin{array}{l}-0.002 \\
(0.002)\end{array}$ \\
\hline 65 and up & $\begin{array}{c}0.004 \\
(0.002)\end{array}$ & $\begin{array}{c}0.003 \\
(0.003)\end{array}$ & $\begin{array}{l}-0.005 \\
(0.004)\end{array}$ & $\begin{array}{c}0.000 \\
(0.003)\end{array}$ \\
\hline Children in household & $\begin{array}{l}-0.003 \\
(0.001)\end{array}$ & $\begin{array}{l}-0.001 \\
(0.002)\end{array}$ & $\begin{array}{l}-0.003 \\
(0.003)\end{array}$ & $\begin{array}{c}0.000 \\
(0.003)\end{array}$ \\
\hline Female & $\begin{array}{l}-0.003 \\
(0.001)\end{array}$ & $\begin{array}{c}0.000 \\
(0.002)\end{array}$ & $\begin{array}{c}0.003 \\
(0.002)\end{array}$ & $\begin{array}{c}0.000 \\
(0.002)\end{array}$ \\
\hline Educ: Less than high school & $\begin{array}{c}0.029 \\
(0.002)\end{array}$ & $\begin{array}{l}-0.008 \\
(0.004)\end{array}$ & $\begin{array}{c}0.004 \\
(0.005)\end{array}$ & $\begin{array}{l}-0.012 \\
(0.006)\end{array}$ \\
\hline Some college or tech. school & $\begin{array}{l}-0.015 \\
(0.001)\end{array}$ & $\begin{array}{l}-0.001 \\
(0.002)\end{array}$ & $\begin{array}{c}0.001 \\
(0.002)\end{array}$ & $\begin{array}{c}0.001 \\
(0.003)\end{array}$ \\
\hline College graduate & $\begin{array}{l}-0.026 \\
(0.001)\end{array}$ & $\begin{array}{c}0.001 \\
(0.002)\end{array}$ & $\begin{array}{c}0.005 \\
(0.002)\end{array}$ & $\begin{array}{c}0.006 \\
(0.002)\end{array}$ \\
\hline Race: Black & $\begin{array}{c}0.042 \\
(0.002)\end{array}$ & $\begin{array}{l}-0.002 \\
(0.004)\end{array}$ & $\begin{array}{l}-0.011 \\
(0.004)\end{array}$ & $\begin{array}{l}-0.011 \\
(0.004)\end{array}$ \\
\hline American Indian & $\begin{array}{c}0.055 \\
(0.005)\end{array}$ & $\begin{array}{l}-0.007 \\
(0.011)\end{array}$ & $\begin{array}{l}-0.020 \\
(0.011)\end{array}$ & $\begin{array}{c}0.017 \\
(0.016)\end{array}$ \\
\hline Asian \& Pacific Islander & $\begin{array}{l}-0.001 \\
(0.002)\end{array}$ & $\begin{array}{c}0.006 \\
(0.003)\end{array}$ & $\begin{array}{c}0.002 \\
(0.004)\end{array}$ & $\begin{array}{c}0.003 \\
(0.004)\end{array}$ \\
\hline Other & $\begin{array}{c}0.022 \\
(0.004)\end{array}$ & $\begin{array}{c}0.013 \\
(0.008)\end{array}$ & $\begin{array}{c}0.005 \\
(0.008)\end{array}$ & $\begin{array}{l}-0.012 \\
(0.009)\end{array}$ \\
\hline Constant & $\begin{array}{c}0.045 \\
(0.004)\end{array}$ & $\begin{array}{c}0.001 \\
(0.008)\end{array}$ & $\begin{array}{l}-0.010 \\
(0.009)\end{array}$ & $\begin{array}{l}-0.025 \\
(0.009)\end{array}$ \\
\hline \multicolumn{5}{|l|}{ B. Adjusted means } \\
\hline Unemployment rate & $\begin{array}{c}0.054 \\
(0.000)\end{array}$ & $\begin{array}{c}0.049 \\
(0.001)\end{array}$ & $\begin{array}{c}0.040 \\
(0.001)\end{array}$ & $\begin{array}{c}0.041 \\
(0.001)\end{array}$ \\
\hline
\end{tabular}

Notes: Source: Current Population Survey, January 2014-March 2020. Sample: Labor force participants in MIS $1, \mathrm{~N}=582,144$. The table reports estimates from a single OLS regression. $R^{2}=0.033$. Dependent variable: $0 / 1$ unemployed indicator. Panel A: estimated coefficients from a fully interacted regression: each regressor is interacted with each difficulty-to-reach category (omitted category: 1 attempt). Regression also includes non-reported indicators (and their interactions) for household size (5), marital status (6), state (51), urban/rural (4), interview month (12) and interview year (7). Panel B: adjusted means, calculated from panel A regression. 
Figure 5: Adjusted Means for Unemployment Rate Over Time

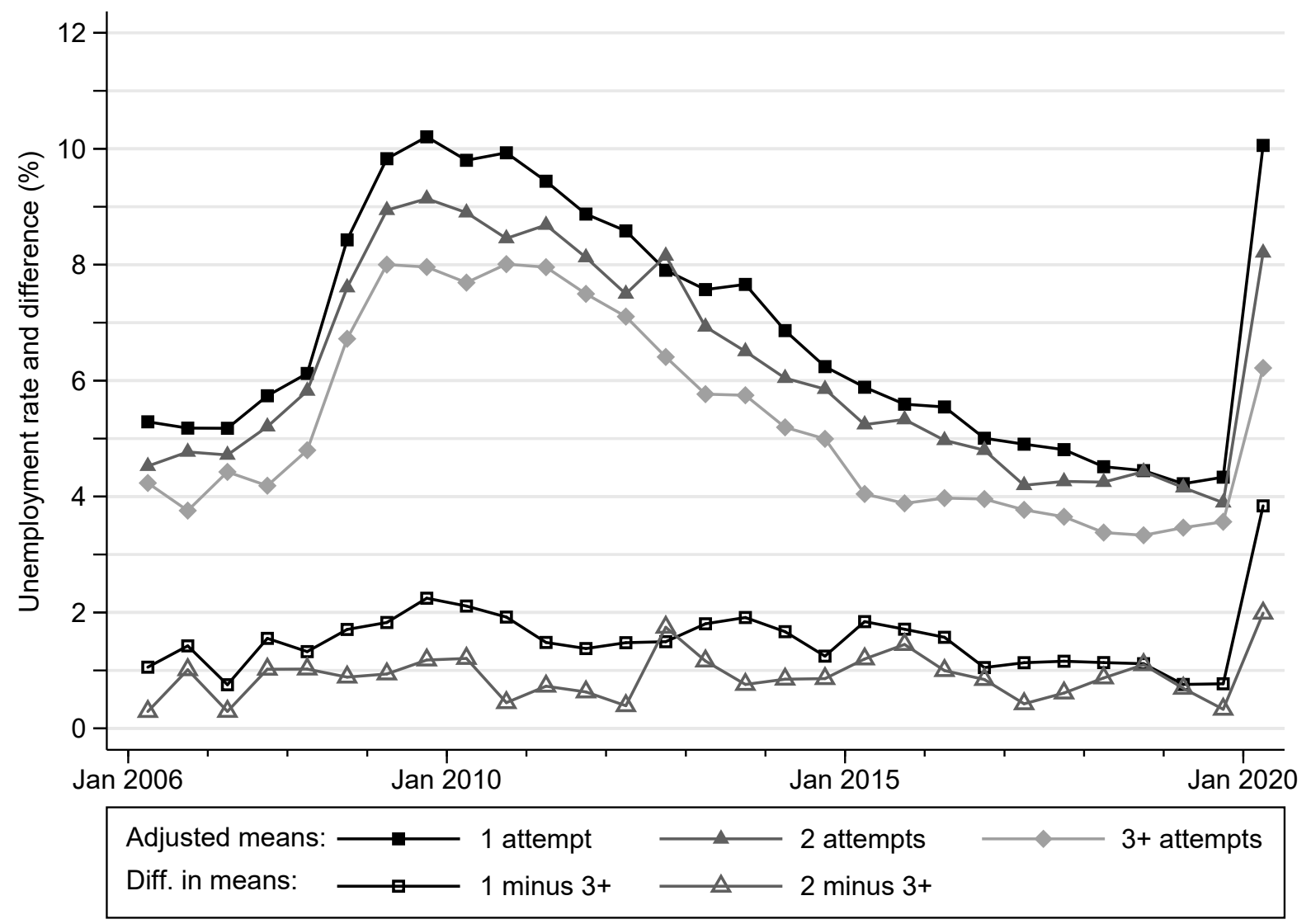

Notes: Source: Current Population Survey, April 2006-September 2020. Sample: All MIS 1 labor force participants. Adjusted means calculated from the regression described in Section IV.1 for each half-year period. Prior to April 2020 all demographics are interacted with difficulty (covariates and interactions identical to Table 4), while April-September 2020 is fully interacted except for omitting the urban/rural interaction with difficulty due to data sparsity. Half-year periods are April-September and October-March. 


\section{IV.2 COVID Update}

Figure 5 s rightmost point shows that during the COVID half-year, the difficulty gradient substantially increases. While the easiest group's UR jumps almost 6 percentage points during this half year - reaching a level close to its Great Recession's peak half-year - the hardest-to-reach group's UR increases by less than 3 percentage points - reaching a level that is almost 2 points below its peak Great Recession levels. That the difference between the groups is so much larger than it was prior to the pandemic, including during the last, comparable half-year peak UR pre-COVID, suggests that the multiplicative difficulty slope dramatically increased.

To quantify this slope increase, we estimate a multiplicative regression (without a constant) of the 1-minus-3+ gap in adjusted-mean UR on the 1-attempt adjusted-mean UR, using the 28 pre-COVID half-year data points. The gap is estimated to be 0.21 (S.E. = 0.01) of 1-attempt UR. Figure 6a shows the predicted value of the gap (as well as that of the $3+$ group, calculable from it) for the 28 pre-COVID half-years and extrapolates this regression-based prediction to the rightmost, COVID half-year. The predicted values closely fit the adjusted means during the 2006-March 2020 period, suggesting a gap of rather stable proportionality (including during the Great Recession). However, during COVID, the multiplicative gap is predicted to be 2.1 percentage points based on past data, while in fact the gap is almost double that, at 3.8 percentage points. This suggests that the nature of the gap between difficulty-of-reaching groups may have dramatically changed during COVID ${ }^{14}$

As discussed in Heffetz and Reeves (2019), our preferred specification is unweighted due to our use of only MIS 1 data in this analysis, whereas the weights are designed for using all data from a given survey period. At the same time, the CPS weighting scheme is designed to correct for some nonresponse, at least on observables. To investigate the effect of weighting on our results, Figure $6 \mathrm{~b}$ replicates the analysis in 6a, except that all half-year adjusted-means are re-estimated, using weighted regressions. Prior to COVID, using weights generally increases the levels of adjusted-mean-UR estimates, but the multiplicative gap is not affected, estimated now at 0.20 (S.E. $=0.01)$ of the 1-attempt UR. However, during

\footnotetext{
${ }^{14}$ Appendix Table A.2 recreates Table 4 for the COVID half-year of April-September 2020. The adjusted means it reports in Panel B are thus those shown in Figure 5 s rightmost point.
} 
Figure 6: Predicted and Actual Difficulty-of-Reaching Gap

(a) Unweighted adjusted means

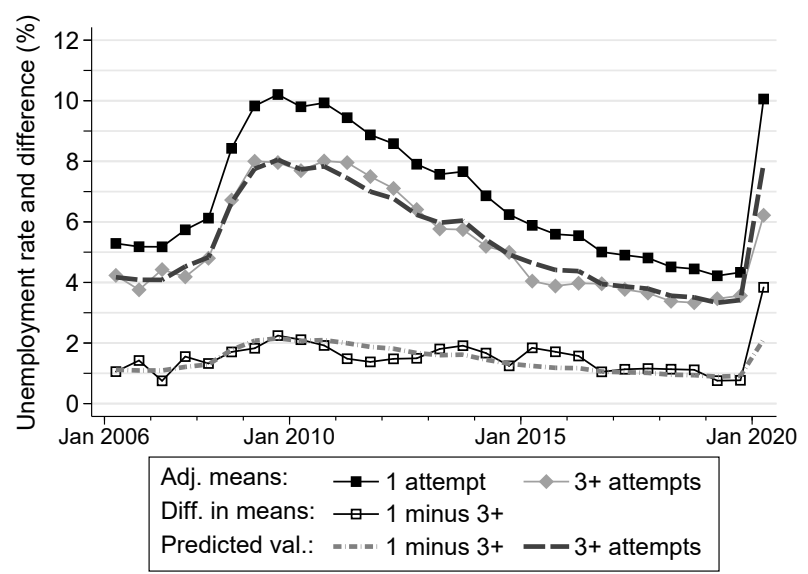

(b) Weighted adjusted means

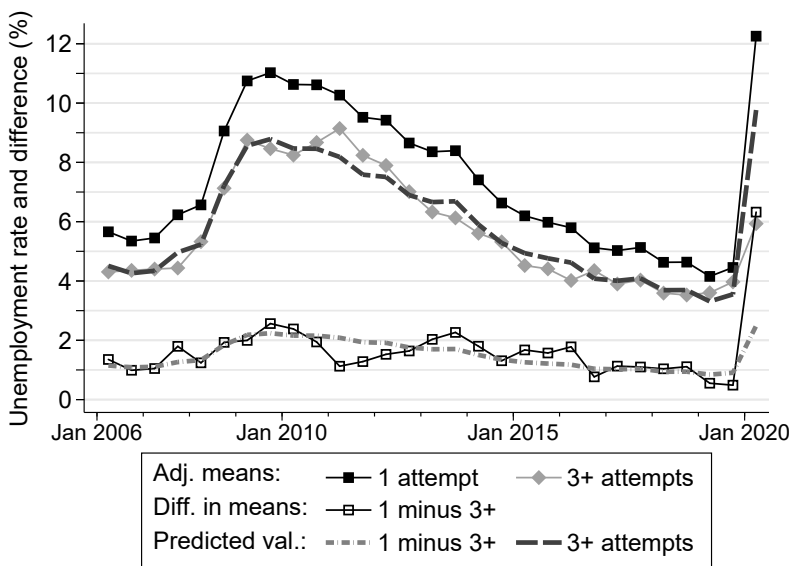

Notes: Source: Current Population Survey, April 2006-September 2020. Sample: MIS 1 labor force participants. Half-year periods are April-September and October-March. Dashed lines: predicted values from multiplicative regression (no constant) of 1-minus-3+ gap on 1-attempt adjusted mean, using only the 2006-March 2020 (i.e., pre-COVID) period, and extrapolating for the rightmost data point (the COVID half-year of April-September 2020). Estimated multiplicative coefficient: (a) slope $=0.21$ (S.E. $=0.01), N$ $=28 ;(\mathrm{b})$ slope $=0.20($ S.E. $=0.01), N=28$.

COVID, the multiplicative gap is predicted to be 2.5 percentage points based on past data, while in fact the gap is almost triple that, at 6.3 percentage points 15

\section{Discussion and Conclusion}

The COVID peak in UR was unlike past peaks. Figure 1, with which we opened and motivated our paper, allows for a comparison with the Great Recession of 2007-2009. It highlights the suddenness and steepness of both the UR peak and the concurrent responserate dip - both owing to the unusual nature of this pandemic-driven crisis. At the same time, the official UR played the same central role it typically plays in macroeconomic crises. A key statistic indicating the state of the economy, it influenced policymakers' real-time decisions

\footnotetext{
${ }^{15}$ As discussed in Section III.2, the weighting does not fully address the issue that the weighted MIS 1 sample is lower in the months of highest unemployment, leading to lower estimates of the UR when the period is pooled. To address this issue, after estimating the weighted regression for the COVID half-year, we also calculate the adjusted means for each difficulty group separately by month, before averaging at the half-year level. Appendix Figure A.2 reproduces Figure 5 twice: using weights A.2 2 ), i.e., using the same specification as Figure 6b; and both using weights and calculating adjusted means at the monthly level for April-September 2020 (A.2 b). The smoothing increases the two easiest groups' means by 0.2 percentage points, while leaving the hardest group's mean virtually unchanged for a net effect of very slightly increasing the overall gap across difficulty groups.
} 
regarding, e.g., relief bills and stimulus packages. Any increases in UR biases thus directly affected both markets and policy.

To what extent did the two biases we study in this paper affect the dramatic increase in official UR that occurred in 2020? Our estimates allow us to conduct illustrative back-ofthe-envelope calculations.

Under the null of no COVID-related change in rotation group bias (which we cannot reject), assuming the bias is indeed multiplicative, assuming that MIS 1 UR is the "real" rate, and using our most recent five-year point estimate for the MIS 1 multiplicative index (Table 3, Panel B), the 11.2 percentage-point increase in the official rate from 3.5 in February to 14.7 in April could have reflected an underlying, larger "real" increase of 12.4 points, from 3.9 percent $(=1.112 \times 3.5)$ to $16.3(=1.112 \times 14.7){ }^{16}$

Similarly, assuming that nonrespondents' UR looks like that of the hardest to reach (the $3+$ group), and that the MIS 1 difficulty slope extends to all MIS - both big assumptions that we have no strong evidence on-and, in addition, that the overall UR approximates that of the easiest-to-reach, we can estimate the approximate magnitude of the potential nonresponse bias. With the response rate at 82.4 percent in February and 69.9 in April (Table 1), our pre-COVID slope estimate of 0.21 (Figure 6a) would suggest, counterfactually, that the "real" unemployment rate could have increased by around 10.4 percentage points, from 3.4 percent to 13.8. However, since our slope estimate during COVID is 81 percent higher than the pre-COVID slope, at 0.38, the "real" rate in April might have actually been just 13.0, implying an unemployment increase of only 9.6 percentage points ${ }^{17}$

We are left to speculate on what might have caused the difficulty slope to almost double. Employed individuals may have remained relatively harder to contact (e.g., as essential

\footnotetext{
${ }^{16}$ We emphasize that these ballpark estimates crucially depend on our assumptions, and should be taken as such. That said, our assumptions, some of which are discussed in Krueger, Mas and Niu (2017), do not seem unreasonable. Solon (1986), for example, also shows theoretically that multiplicative rotation group differences would bias estimates of month-to-month changes in UR, and presents empirical evidence that the bias is not additive. Furthermore, one could replace any one of our specific assumptions with an alternative. For example, if we use the MIS 1 multiplicative-index estimate of Krueger, Mas and Niu (2017) for 1994-2014, the "real" change in unemployment would be from 3.8 percent $(=1.092 \times 3.5)$ to $16.1(=1.092 \times 14.7)$, while using our 2006-March 2020 estimate yields a change from 3.9 percent $(=1.101 \times 3.5)$ to $16.2(=1.101 \times 14.7)$.

${ }^{17}$ We calculate these numbers as follows. With a pre-COVID slope of 0.21: 3.4 percent in February $(=0.824 \times 3.5+(1-0.824) \times(1-0.21) \times 3.5)$ and 13.8 in April $(=0.699 \times 14.7+(1-0.699) \times(1-0.21) \times 14.7)$. With a COVID-time slope of 0.38: 13.0 percent in April $(=0.699 \times 14.7+(1-0.699) \times(1-0.38) \times 14.7)$.
} 
workers or juggling work with increased family responsibilities from the lockdown). On the other hand, the unemployed may have gotten relatively easier to contact - the pandemic having stopped them from visiting many of the places and doing many of the things that might otherwise keep them away from home. Consistent with this possibility, as we note in Section II.2, the relative share of respondents in the easiest-to-reach category increased dramatically during COVID.

Our paper joins a quickly growing literature concerned with the effect of COVID-19 on both surveys and the outcomes they measure. We find a COVID-specific increase in the difficulty gap in UR, suggesting a potential change in the nature of nonresponse bias. Ward and Edwards (2020) examine a particular potential source of change in nonresponse bias, the stoppage of in-person interviews, and find evidence suggestive of changing nonresponse patterns impacting unemployment estimates within racial groups. While these findings hint that researchers need to take extra care when examining UR during COVID, two other papers suggest similar caution when studying other outcomes. By linking administrative and survey data, Rothbaum and Bee (2020) find significant changes in demographic composition and income in the 2020 CPS ASEC. Similarly, Berchick, Mykyta and Stern (2020) find composition changes that led to impacts on the estimates for employer-sponsored insurance coverage by comparison to the American Community Survey, which was not disrupted by COVID.

The CPS serves not only as the source for real-time indicators of the economy's health; it is also already an important resource for researchers trying to understand the income impacts of the government's response to COVID (Han, Meyer and Sullivan, 2020). Nonresponse is a source of potentially significant error in the measurement of transfer income (Meyer, Mok and Sullivan, 2015). The unique nature of the COVID disruption, combined with our finding of a historically unusual difficulty gradient in UR, highlight the importance of considering nonresponse in any analysis of COVID time. They also suggest potentially adopting time-period specific corrective measures to address COVID's anomalous effects. While investigating potential survey biases is always important, our evidence in this paper suggests that biases that are of academic interest in normal times may have assumed disproportional roles during COVID. Further understanding them, and investigating ways to 
account for them, should remain high on researchers' agenda.

Future research could investigate which of the different COVID-related changes that we and the other new papers document are temporary, and to what extent some of them may leave longer-term marks. For example, changes in commuting, travel, distant learning, or location preferences could all affect both the composition of responding households and their response behavior going forward. Future studies in other countries could offer welcome variation in survey design, implementation, and context-including, e.g., in political attitudes and trust in institutions - which could, again, affect respondents' composition and behavior. Indeed, Krueger, Mas and Niu (2017) mention that in an earlier version of their paper they find no rotation group bias in UR calculated from the Canadian labor force survey, suggesting that the bias "is not an inherent feature of repeated labor force surveys," and highlighting the promise of learning from other contexts. Finally, as the pandemic hit different countries to different degrees, such comparisons could provide an additional source of variation, specific to the time of COVID.

\section{References}

Bailar, Barbara A. 1975. "The Effects of Rotation Group Bias on Estimates from Panel Surveys." Journal of the American Statistical Association, 70(349): 23-30.

Berchick, Edward R., Laryssa Mykyta, and Sharon M. Stern. 2020. "The Influence of COVID-19-Related Data Collection Changes on Measuring Health Insurance Coverage in the 2020 CPS ASEC." U.S. Census Bureau Working Paper 2020-13.

BLS. 2020a. "Impact of the coronavirus (COVID-19) pandemic on The Employment Situation for November 2020." https://www.bls.gov/covid19/ employment-situation-covid19-faq-november-2020.htm (accesssed December 08, 2020).

BLS. 2020b. "Table A-15. Alternative measures of labor underutilization." https://www. bls.gov/webapps/legacy/cpsatab15.htm (accesssed December 08, 2020).

CPS. 2015. "Current Population Survey Interviewing Manual." https://www2.census. gov/programs-surveys/cps/methodology/intman/CPS_Manual_April2015.pdf （ac- 
cessed December 08, 2020).

CPS. 2020a. "Frequently asked questions: The impact of the coronavirus (COVID-19) pandemic on The Employment Situation for March 2020." https://www.bls.gov/cps/ employment-situation-covid19-faq-march-2020.pdf (accesssed December 08, 2020).

CPS. 2020b. "Labor Force Statistics from the Current Population Survey: Concepts and Definitions." https://www.bls.gov/cps/definitions.htm (accesssed December 08, 2020).

Han, Jeehoon, Bruce D. Meyer, and James X. Sullivan. 2020. "Income and Poverty in the COVID-19 Pandemic." National Bureau of Economic Research Working Paper 27729.

Heffetz, Ori, and Daniel B. Reeves. 2019. "Difficulty of Reaching Respondents and Nonresponse Bias: Evidence from Large Government Surveys." Review of Economics and Statistics, 101(1): 176-191.

Krueger, Alan B., Alexandre Mas, and Xiaotong Niu. 2017. "The Evolution of Rotation Group Bias: Will the Real Unemployment Rate Please Stand Up?" Review of Economics and Statistics, 2(99): 258-264.

Meyer, Bruce D., Wallace Mok, and James X. Sullivan. 2015. "Household Surveys in Crisis." Journal of Economic Perspectives, 29(4): 199-226.

Potthoff, Richard F., Kenneth G. Manton, and Max A. Woodbury. 1993. "Correcting for Nonavailability Bias in Surveys by Weighting Based on Number of Callbacks." Journal of the American Statistical Association, 88(424): 1197-1207.

Rothbaum, Jonathan, and Adam Bee. 2020. "Coronavirus Infects Surveys, Too: Nonresponse Bias During the Pandemic in the CPS ASEC." U.S. Census Bureau Working Paper SEHSD WP2020-10.

Solon, Gary. 1986. "Effects of Rotation Group Bias on Estimation of Unemployment." Journal of Business and Economic Statistics, 4(1): 105-109.

Ward, Jason M., and Kathryn Anne Edwards. 2020. "Statistics in the Time of Coronavirus: COVID-19-related Nonresponse in CPS Household Survey." RAND Corporation Working paper WRA842-1. 


\section{A Appendix}

Table A.1: Effect of COVID on Rotation Group Bias

\begin{tabular}{lcc}
\hline \hline & $(1)$ & $(2)$ \\
\hline Time & 0.000060 & 0.000060 \\
& $(0.000070)$ & $(0.000070)$ \\
COVID & 0.60 & 0.77 \\
& $(0.59)$ & $(0.82)$ \\
COVID $\times$ Time & & -0.004 \\
& & $(0.012)$ \\
Constant & -1.88 & -1.88 \\
& $(0.21)$ & $(0.21)$ \\
\hline Observations & 59 & 59 \\
$R^{2}$ & 0.044 & 0.045 \\
\hline Notes: Sourc
\end{tabular}

Notes: Source: Current Population Survey, January 2006-September 2020. OLS regressions. Dependent variable: slope of rotation group bias for each quarter. Time: linear trend. COVID: indicator $=1$ for the two quarters starting in April 2020, $=0$ otherwise. 
Table A.2: Unemployment Rate by Difficulty, COVID Half-Year

\begin{tabular}{|c|c|c|c|c|}
\hline Attempts & 1 & 2 & $3+$ & NR \\
\hline \multicolumn{5}{|l|}{ A. Regression with interactions } \\
\hline & Base & \multicolumn{3}{|c|}{ Interactions } \\
\hline Age: $16-19$ & $\begin{array}{c}0.017 \\
(0.030)\end{array}$ & $\begin{array}{c}0.028 \\
(0.069)\end{array}$ & $\begin{array}{l}-0.092 \\
(0.075)\end{array}$ & $\begin{array}{l}-0.002 \\
(0.035)\end{array}$ \\
\hline $20-39$ & $\begin{array}{l}-0.008 \\
(0.010)\end{array}$ & $\begin{array}{l}-0.009 \\
(0.025)\end{array}$ & $\begin{array}{c}0.010 \\
(0.027)\end{array}$ & $\begin{array}{c}0.026 \\
(0.011)\end{array}$ \\
\hline $50-64$ & $\begin{array}{c}0.009 \\
(0.011)\end{array}$ & $\begin{array}{l}-0.033 \\
(0.023)\end{array}$ & $\begin{array}{c}-0.039 \\
(0.030)\end{array}$ & $\begin{array}{l}-0.020 \\
(0.012)\end{array}$ \\
\hline 65 and up & $\begin{array}{c}0.002 \\
(0.016)\end{array}$ & $\begin{array}{l}-0.014 \\
(0.033)\end{array}$ & $\begin{array}{c}0.051 \\
(0.059)\end{array}$ & $\begin{array}{c}0.006 \\
(0.018)\end{array}$ \\
\hline Children in household & $\begin{array}{l}-0.013 \\
(0.011)\end{array}$ & $\begin{array}{c}0.028 \\
(0.028)\end{array}$ & $\begin{array}{l}-0.023 \\
(0.031)\end{array}$ & $\begin{array}{l}-0.015 \\
(0.013)\end{array}$ \\
\hline Female & $\begin{array}{c}0.001 \\
(0.007)\end{array}$ & $\begin{array}{c}0.042 \\
(0.017)\end{array}$ & $\begin{array}{c}0.029 \\
(0.020)\end{array}$ & $\begin{array}{c}0.023 \\
(0.008)\end{array}$ \\
\hline Educ: Less than high school & $\begin{array}{c}0.012 \\
(0.019)\end{array}$ & $\begin{array}{l}-0.041 \\
(0.041)\end{array}$ & $\begin{array}{c}0.109 \\
(0.061)\end{array}$ & $\begin{array}{c}0.005 \\
(0.022)\end{array}$ \\
\hline Some college or tech. school & $\begin{array}{l}-0.017 \\
(0.011)\end{array}$ & $\begin{array}{l}-0.014 \\
(0.023)\end{array}$ & $\begin{array}{c}0.001 \\
(0.032)\end{array}$ & $\begin{array}{l}-0.004 \\
(0.013)\end{array}$ \\
\hline College graduate & $\begin{array}{l}-0.042 \\
(0.010)\end{array}$ & $\begin{array}{l}-0.002 \\
(0.024)\end{array}$ & $\begin{array}{l}-0.031 \\
(0.027)\end{array}$ & $\begin{array}{l}-0.022 \\
(0.011)\end{array}$ \\
\hline Race: Black & $\begin{array}{c}0.040 \\
(0.016)\end{array}$ & $\begin{array}{l}-0.030 \\
(0.032)\end{array}$ & $\begin{array}{c}0.025 \\
(0.039)\end{array}$ & $\begin{array}{l}-0.001 \\
(0.019)\end{array}$ \\
\hline American Indian & $\begin{array}{c}0.006 \\
(0.037)\end{array}$ & $\begin{array}{l}-0.010 \\
(0.061)\end{array}$ & $\begin{array}{c}0.200 \\
(0.140)\end{array}$ & $\begin{array}{c}0.022 \\
(0.045)\end{array}$ \\
\hline Asian & $\begin{array}{c}0.036 \\
(0.020)\end{array}$ & $\begin{array}{l}-0.021 \\
(0.045)\end{array}$ & $\begin{array}{l}-0.006 \\
(0.041)\end{array}$ & $\begin{array}{l}-0.011 \\
(0.023)\end{array}$ \\
\hline Other & $\begin{array}{c}0.019 \\
(0.033)\end{array}$ & $\begin{array}{l}-0.039 \\
(0.062)\end{array}$ & $\begin{array}{c}0.085 \\
(0.139)\end{array}$ & $\begin{array}{c}0.005 \\
(0.039)\end{array}$ \\
\hline Constant & $\begin{array}{c}0.066 \\
(0.042)\end{array}$ & $\begin{array}{l}-0.005 \\
(0.073)\end{array}$ & $\begin{array}{l}-0.048 \\
(0.085)\end{array}$ & $\begin{array}{c}0.020 \\
(0.046)\end{array}$ \\
\hline \multicolumn{5}{|l|}{ B. Adjusted means } \\
\hline Unemployment rate & $\begin{array}{c}0.101 \\
(0.007)\end{array}$ & $\begin{array}{c}0.082 \\
(0.015)\end{array}$ & $\begin{array}{c}0.062 \\
(0.017)\end{array}$ & $\begin{array}{c}0.096 \\
(0.002)\end{array}$ \\
\hline
\end{tabular}

Notes: Source: Current Population Survey, April-September 2020. Sample: Labor force participants in MIS $1, \mathrm{~N}=29,246$. The table reports estimates from a single OLS regression. $R^{2}=0.051$. Dependent variable: 0/1 unemployed indicator. Panel A: estimated coefficients from a fully interacted regression: each regressor is interacted with each difficulty-to-reach category (omitted category: 1 attempt). Regression also includes non-reported indicators (and their interactions) for household size (5), marital status (6), state (51), urban/rural (3, not interacted with difficulty), and interview month (6). Panel B: adjusted means, calculated from panel A regression. 
Figure A.1: CPS Demographics, All MIS
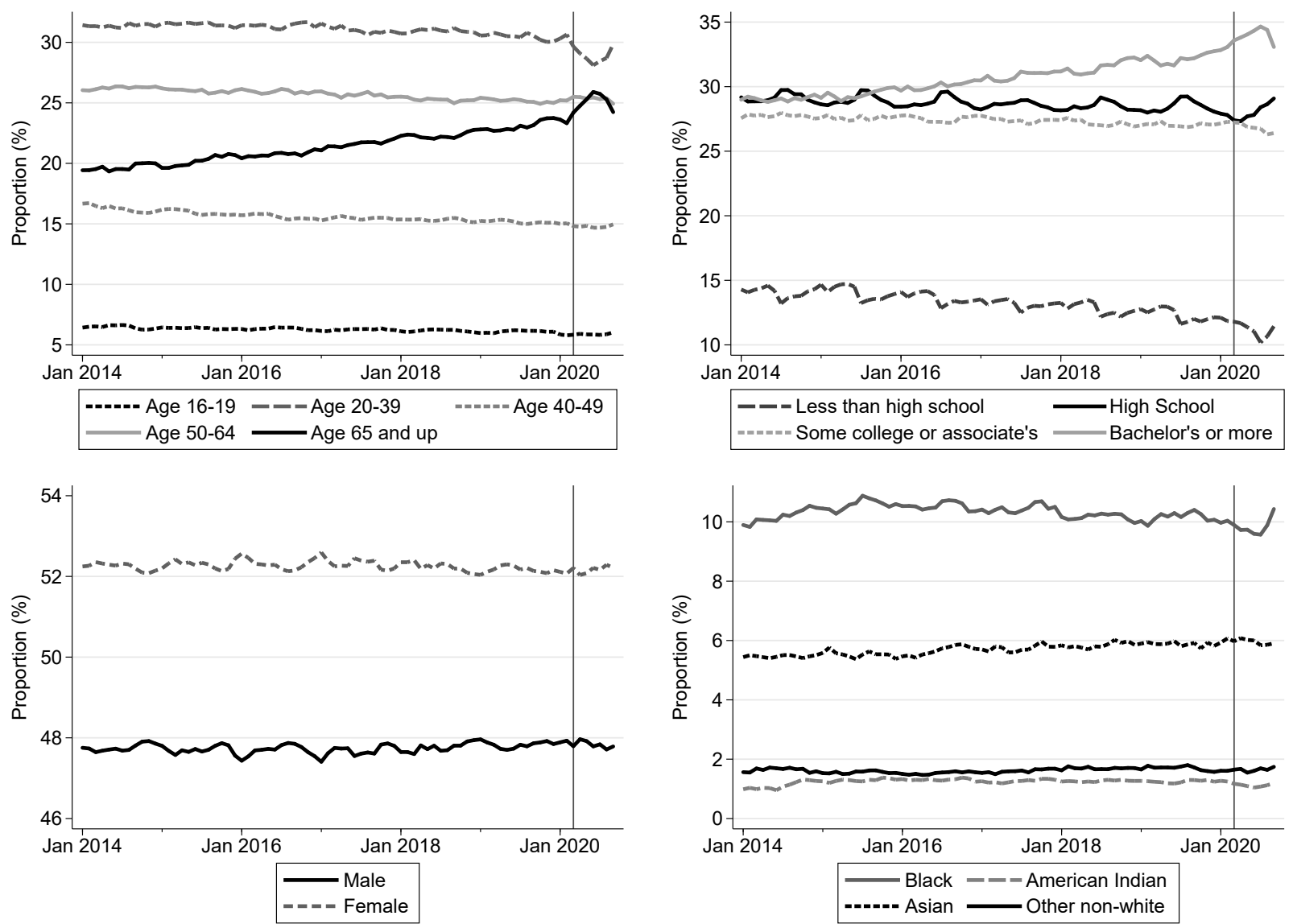

Notes: Source: Current Population Survey, January 2014-September 2020. Sample: all participants. Share in each demographic group (share White not graphed). Vertical line at March 2020. 
Figure A.2: Adjusted Means for Unemployment Rate, Alternative Specifications

(a) Weighted adjusted means

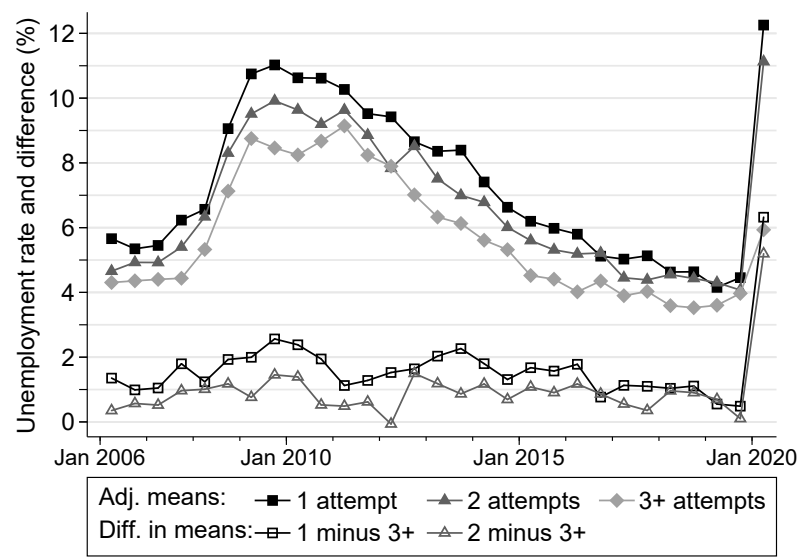

(b) Weighted adj. means, smoothed from monthly

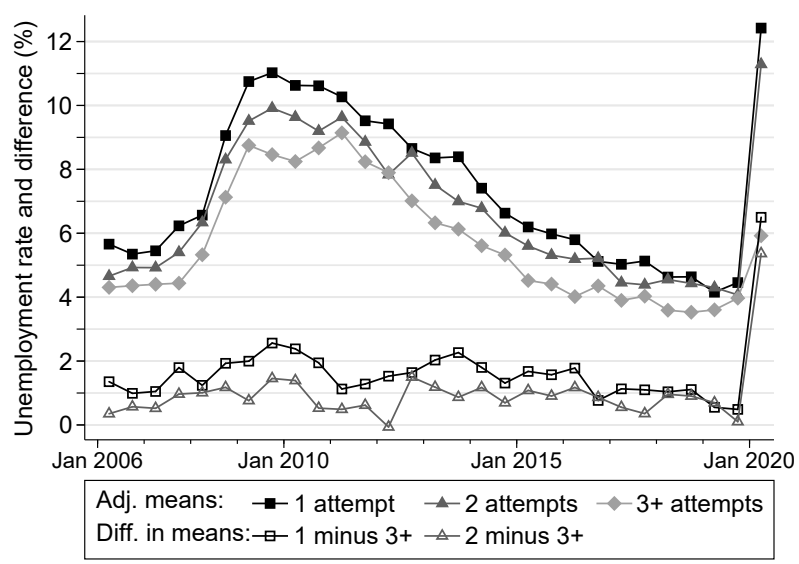

Notes: Source: Current Population Survey, April 2006-September 2020. Sample: MIS 1 labor force participants. Half-year periods are April-September and October-March. (a): Figure 5 recreated using CPS weights. (b): Figure 5 recreated using CPS weights, but rightmost data point (the COVID half-year of April-September 2020) is the average of six monthly-level estimates (see text for full details). 